\title{
El nosotros y los otros en los discursos del presidente ecuatoriano Lenín Moreno durante 2018
}

\author{
"Us" and "Others" in Ecuadorian president Lenín Moreno's speeches \\ during 2018
}

\section{Byron Andino}

Universidad Nacional de La Plata, La Plata, Argentina

bayron.andinolaperio.unlp.edu.ar

\section{Resumen}

El artículo analiza los discursos del mandatario ecuatoriano Lenín Moreno (2017-2021) a partir de la construcción de los prodestinatarios y los contradestinatarios, es decir, de un nosotros y un otros, con sus representaciones positivas y negativas. El estudio indaga en la estrategia discursiva del presidente en el contexto de Ecuador durante el año 2018, cuando Moreno asume una lógica política del consenso para su articulación con grupos de poder y que su nuevo opositor sea su excorreligionario y exmandatario Rafael Correa, a quien se dirigen todos los ataques mediante las entidades del imaginario y con una reescritura de lo que fue ese gobierno. Los resultados del análisis del discurso político evidencian un abandono de categorías aglutinadoras del nosotros en la "Revolución Ciudadana" de Correa a "El Gobierno de todos" de Moreno.

Palabras clave: análisis de discurso; discurso político; Ecuador; política; gobierno de consenso.

\begin{abstract}
The article analyzes speeches of the Ecuadorian president, Lenín Moreno, regarding the process of building up the concepts of the prodestinatarios and the contradestinatarios: that is, a binary representation of "Us" and "Others", implying positive and negative depictions. The study explores the president's discursive strategy in the Ecuadorian political realm during 2018. That year, Moreno adopted a political frame of consensus to articulate his administration with powerful groups. And, in doing so, his former political partner and expresident, Rafael Correa, became Moreno's new opponent. Political attacks, then, targeted Correa relying upon and rewriting what was such administration. There is, also, an erasing allowing to put together an "Us" in Correa's "Citizenship Revolution" turned into Moreno's "Government of everybody".
\end{abstract}

Keywords: discourse analysis; political speech; Ecuador; politics; consensus Government. 


\section{Introducción}

Este artículo analiza los discursos del presidente de Ecuador, Lenín Moreno, durante 2018, transmitidos por televisión a través de cadenas y entrevistas. El objetivo es indagar la estrategia discursiva (Verón, 1987) que incluye construir renovados nosotros y otros, acorde a su cambio estratégico a una lógica del consenso político. Por ello, enfatizamos un análisis de los contenidos que procuren generar efectos de sentido, más que de lo lingüístico.

El momento de producción discursiva (2018) es posterior a los 10 años de gobierno de Rafael Correa, de quien Lenín Moreno fue vicepresidente (2007-2013) y compañero de militancia en Alianza PAIS'. Moreno afirmaba que su ideología era de izquierda (por ejemplo, fue militante del Movimiento de Izquierda Revolucionaria -MIR- en los años '70), pero tuvo una ruptura progresiva con su antecesor desde que asumió el mandato el 24 de mayo de 2017. Dicho quiebre produjo una deconstrucción del orden político en el país (Ganuza, 2019) debido a que Moreno se distanció de la lógica confrontacional que adoptó Correa y las coaliciones de aliados y opositores radicalizaron su cambio para conseguir apoyo incluso de la derecha y de grupos económicos tradicionalmente poderosos en Ecuador.

Maingueneau (2012) afirma que la relevancia del análisis de discurso radicaría en "aprehender el discurso como articulación de textos y lugares sociales" (p. 4). Sobre el discurso político, Van Dijk (1999b) concuerda con que se definiría contextualmente y no debe limitarse a las propiedades estructurales del texto. Lo discursivo se entiende como una forma más amplia que lo lingüístico o lo verbal, pues tiene relación con el proceso de construcción social de sentido, como lo ha considerado, por ejemplo, Ernesto Laclau (2005).

Este artículo está organizado así: Primero, se expone el marco teórico y la metodología del análisis de discurso. Luego, se describe el control del contexto político-mediático en el gobierno de Lenín Moreno que ilustra el manejo de la situación comunicativa; abordaremos la construcción de un nosotros y un Otros mediante los destinatarios; y, por último, mostraremos cómo el Presidente Lenín Moreno figura el pasado y el presente.

\section{Marco teórico}

El campo de la política posee una dimensión antagónica mediante la cual se configura un orden social hegemónico que es producto de decisiones sociales y contextuales, por lo que no hay un orden esencial ni absoluto. Estas prácticas hegemónicas son de articulación para configurar lo social como expresión de las relaciones de poder (Mouffe, 2014).

La política se forma en esas articulaciones que construyen, simultáneamente, un nosotros y un otros, proceso en el cual el discurso tiene un rol central. Eliseo Verón (1987) indica que lo político implica enfrentamiento con otros enunciados, la relación con un enemigo, una lucha entre enunciadores como una dimensión polémica del discurso. En cuanto a la formación de los otros, Teun van Dijk (1999b) sostiene que se trataría de competidores ideológicos y adversarios relacionados con los sistemas políticos, instituciones, procesos y actores. Ante ellos se ejerce un principio estratégico: se limita al texto político como evaluación dicotómica que enfatiza o minimiza a favor o en contra del nosotros y de los otros.

En cambio, si existiera un régimen de identidad (acuerdo) de toda la comunidad consigo misma se trataría de una lógica de consenso porque el orden sería perfecto ligualdad de cualquiera con cualquiera), por lo que no habría conflicto por lo configurado. Pero no es así: los grupos subalternos no forman parte de lo social y los sectores de poder han acudido a una lógica de consenso como intento de inmovilidad social para evitar el cambio: "Es la desaparición de toda diferencia entre parte de un litigio y parte de la sociedad. Es la desaparición (...) del litigio abiertos por el nombre del pueblo y el vacío de su libertad. Es, en suma, la desaparición de la política" (Rancière, 1996, p. 130).

En este punto, siguiendo a Rancière, aparece un "régimen de opinión", como una desaparición de las prácticas de tensión de los sujetos en la opinión pública. Sería una realidad simulada de supuesta igualdad de criterios entre las partes, lo que oculta las injusticias y formas de dominio. Con estas acciones esconde que, en realidad, se forma un nosotros y un otros jerárquico, donde los primeros tienen parte y los segundos, no (Rancière, 1996). 
Es esta intersección en la cual este estudio indaga: el consenso para ocultar la nuevas articulaciones de poder, con su consiguiente construcción de aliados y opositores.

Para ello consideramos, también, el "control del contexto" (Van Dijk, 1999a, p. 27); es decir, el dominio de los recursos en la situación comunicativa, sus participantes y qué acciones sociales se incluirían en la cobertura mediática, en eventos oficiales de Gobierno y en el marco de otros tipos de difusión que respondan a la estrategia discursiva.

Como punto central tenemos las formas de constitución de los destinatarios. Verón considera que todo acto de enunciación política implica una respuesta opuesta, está habitado por un otro negativo y un nosotros positivo:

\begin{abstract}
El destinatario positivo es esa posición que corresponde a un receptor que participa de las mismas ideas, que adhiere a los mismos valores y persigue los mismos objetivos que el enunciador: el destinatario positivo es antes que todo el partidario. Hablaremos en su caso de prodestinatario (...). El destinatario negativo está, por supuesto, excluido del colectivo de identificación: esta exclusión es la definición misma del destinatario negativo (...) lo llamaremos contradestinatario (Verón, 1987, p.17).
\end{abstract}

Procuramos analizar los elementos relevantes que no cambian en distintos discursos. Estudiar la construcción del nosotros es buscar sentidos de pertenencia para la configuración de identidades, a la vez que los otros se forjan a partir de límites preestablecidos.

Estas maneras de situarse a sí mismo y a los destinatarios son concebidas por Verón como "estrategias discursivas". Para hacerlo construye vínculos mediante los colectivos de identificación, además de otras relaciones con las entidades del imaginario. En el presente estudio agregamos el componente descriptivo:

- Entidades del imaginario y colectivo de identificación: Formados por la relación entre el enunciador y el prodestinatario, muestra el nosotros inclusivo. En caso de entrar en relación con el contradestinatario la designación será otra y tendrá sentido negativo.
- Componente descriptivo: Es aquel en que el enunciador ejercita la constatación, hace un balance de una situación que incluye lecturas del pasado y de la actualidad.

\section{Marco metodológico}

Este estudio se inscribe en un enfoque cualitativo para el análisis del discurso político. Se trata de una investigación sobre la estrategia discursiva de Moreno para indagar qué articulaciones de bloques de poder en Ecuador construye y cómo los forja discursivamente.

Nuestro corpus de discursos del Presidente Lenín Moreno está conformado por 17 contenidos televisivos (del año 2018) que fueron recuperados -en su mayoría- del canal YouTube oficial de la Presidencia de la República del Ecuador. Son transmisiones oficiales de información que incluyen: El Gobierno de todos, El Presidente informa, cadenas nacionales, mensajes del Presidente, declaraciones públicas. A ese material sumamos entrevistas de Moreno concedidas a medios de comunicación regionales, nacionales y extranjeros. Algunos de esos textos ya estaban disponibles en la web oficial de la Presidencia de la República y se transcribió el resto.

Utilizamos, adaptamos y combinamos las categorías propuestas por Eliseo Verón y Teun A. van Dijk para diseñar el dispositivo de indagación para el análisis del discurso (ver Tabla 1).

A la luz del marco teórico discutido anteriormente y a la estrategia metodológica de carácter cualitativa descrita, el objetivo central del estudio fue indagar la estrategia discursiva para construir a los otros y el nosotros. Para ello, analizamos el material de acuerdo a las categorías descritas. 1) Control del contexto: la situación comunicativa y los recursos mediáticos a disposición del Presidente; 2) Destinatarios: análisis de discurso de prodestinatarios y contradestinatarios para conocer la construcción del nosotros y los otros lque tendrá otros indicadores como el componente descriptivo y las entidades del imaginario). El análisis desarrollado fue interpretativo y, con una observación detallada, construimos categorías analíticas que vinculamos a los conceptos señalados para concentrarnos en sus contenidos. 
Tabla 1: Esquema de metodología

\begin{tabular}{|c|c|c|}
\hline UNIDAD DE ANÁLISIS & \multicolumn{2}{|l|}{ VARIABLES } \\
\hline $\begin{array}{l}\text { Discursos de Lenín Moreno } \\
\text { durante } 2018\end{array}$ & \multicolumn{2}{|c|}{$\begin{array}{l}\text { Estrategia discursiva bajo la lógica del consenso: } \\
\text { control del contexto y destinatarios }\end{array}$} \\
\hline $\begin{array}{l}\text { Control del contexto } \\
\text { (Van Dijk) }\end{array}$ & \multicolumn{2}{|c|}{$\begin{array}{l}\text { Situación comunicativa } \\
\text { Acciones y capacidad de difusión } \\
\text { Relación con los medios de comunicación }\end{array}$} \\
\hline \multirow[t]{2}{*}{$\begin{array}{l}\text { Destinatarios } \\
\text { (Verón) }\end{array}$} & Prodestinatario & $\begin{array}{l}\text { Entidades del imaginario: colectivos de identificación, } \\
\text { meta colectivos singulares, formas nominales con po- } \\
\text { der explicativo }\end{array}$ \\
\hline & Contradestinatario & Componente descriptivo \\
\hline
\end{tabular}

\section{Control del contexto: la comunicación en el gobierno de Lenín Moreno}

En 2018, Ecuador tenía dificultades económicas derivadas de la deuda pública, el bajo crecimiento económico proyectado y numerosos casos de corrupción denunciados e investigados en contra de la administración de Rafael Correa. El gobierno de Moreno, entonces, dio un giro en cuanto a política económica y, por lo tanto, a las articulaciones de poder en la sociedad ecuatoriana. Para ello requería el soporte de varios sectores y actores para impulsar ese cambio, uno de ellos correspondía al mediático.

Teun van Dijk (1999a) sostiene que es indispensable considerar cómo se vinculan y entrelazan los grupos de élite con el discurso para ejercer el poder contra otros. Sus recursos les permiten tener acceso al discurso público, con ellos pueden incidir en la esfera pública. Siguiendo a Van Dijk, para controlar el discurso público es necesario controlar el contexto, que implica definir la situación comunicativa: su espacio, tiempo, las acciones en curso y sus actores, sus representaciones mentales y los conocimientos. Sobre este punto en particular seguimos algunos de los argumentos desarrollados por Waisbord (2014) para analizar cómo el gobierno de Moreno ha desplegado su modelo comunicativo.
Primero, en lo referente a la comunicación gubernamental y debido a los fuertes ajustes al presupuesto fiscal, el gobierno de Moreno eliminó la Secretaría Nacional de Comunicación y la transformó en una Secretaría adjunta a la Presidencia, sin la estructura ni el presupuesto que tenía previamente. El gobierno eliminó el programa sabatino televisado y por radio "Enlace Ciudadano"2, pilar en la estrategia comunicativa de Correa. En reemplazo, el gobierno de Moreno desarrolló dos productos breves mediante los que difunde sus obras, acciones y manifiesta su opinión sobre temas específicos. El primero es "El Gobierno de Todos", transmitido los lunes y que dura entre 7 y 8 minutos. El segundo es el "Mensaje del Presidente" lentre 3 y 4 minutos) en el que Moreno incluye su postura oficial sobre hechos de coyuntura del país. A esto se suman eventuales cadenas nacionales.

Segundo, en cuanto a los medios bajo la órbita o influencia de la presidencia, Lenín Moreno ordenó el cierre del gubernamental Ciudadano TV, así como de la Agencia Pública de Noticias ANDES. Fusionaron los noticieros del medio público Ecuador TV y del medio privado incautado 3 Gamavisión para formar Telediario, se unificaron en una línea editorial que seguiría manejada desde el gobierno. En el diario El Telégrafo ${ }^{4}$, el gobierno realizó numerosos cambios en sus mandos ejecutivos superiores: reclutaron profesionales provenientes de medios privados y quienes, incluso, habían sido opositores o críticos a la gestión de Correa. Algo 
similar ocurrió en Radio Pública (Pública FM). En el canal incautado TC, finalmente, las jefaturas se mantuvieron sin cambios y solo se actualizó la línea editorial diseñada desde el gobierno.

Tercero, se renovaron las relaciones entre el gobierno de Moreno y los medios privados. Dado el cambio a la política de consenso, la relación tuvo un enfoque menos beligerante que la de su antecesor, Rafael Correa. En ese marco, Moreno convocó a propietarios o representantes de compañías de medios de comunicación a reuniones reservadas. Las lealtades económicas se repararon y el Estado ha vuelto a asignar pauta publicitaria a medios de comunicación que habían quedado fuera de dicho financiamiento. En cuanto a los medios privados de cobertura nacional, el encuadre de la información sobre la labor gubernamental, en general, y del Presidente en particular, se caracterizaba por no dañar mayormente al gobierno de Moreno, por reproducir las líneas discursivas del presidente y por enfatizar ataques contra el anterior mandato de la llamada Revolución Ciudadana.

Cuarto, en cuanto a la construcción de la imagen del Presidente, la presencia mediática directa de Moreno es baja en comparación con la personalización de la política encarnada previamente por Correa. Bajo la administración de Moreno han sobresalido otras figuras, como el vicepresidente Otto Sonnenholzner ${ }^{5}$, ministros y consejeros presidenciales que han actuado como voceros.

Por último, sobre las leyes de regulación en comunicación, en lo que se ha leído como una respuesta a las presiones de los grupos de poder políticos y mediáticos, el gobierno de Moreno reformó la Ley Orgánica de Comunicación ${ }^{6}$. La normativa mantuvo una mención ideal de reconocimiento evocativo de derechos, pero la reforma suprimió la Superintendencia de Información y Comunicación como entidad de regulación de contenidos y que disponía el cumplimiento de la ley en cuanto a lo administrativo. Este cambio debilitó las herramientas para exigir el cumplimiento de los derechos a la comunicación. Esta reforma implicó modificar la reserva del espacio radioeléctrico para otorgar privilegios a los medios privados, mantener (en el papel, al menos) el espacio de los medios comunitarios, así como mantener a los medios públicos reducidos ${ }^{7}$ y con un rol muy disminuido.

\section{Entidades del imaginario político: “El Gobierno de todos" y su nuevo otro}

La relación entre el hablante y el destinatario se forja a través de entidades del imaginario político construidas con el discurso. Verón (1987) sostiene que los "colectivos de identificación" son entidades que muestran un nosotros inclusivo con su prodestinatario. En caso de relacionarse con el contradestinatario, la designación tendrá sentido negativo. También se cuentan las "entidades más amplias" que los colectivos de identificación, enfocadas más bien en el paradestinatario (el indeciso). Finalmente, consideramos los "meta-colectivos singulares", los cuales no admiten cuantificación y son más generales que los colectivos. En esta búsqueda de las entidades indagamos a quiénes y cómo Moreno nombra como prodestinatarios y contradestinatarios.

\subsection{Un nosotros reducido a lo institucional}

Exploramos cómo se constituyen el nosotros y los otros en el plano enunciativo. No existieron tantas formas reiterativas de colectivos de identificación para prodestinatarios ni para contradestinatarios, sino que, más bien, habría una dispersión según hechos coyunturales. La concepción de su proyecto político pasó de la identificación ideológica a lo institucional.

\subsubsection{Nosotros los de izquierda y algunas ambigüedades}

Al inicio de 2018, los periodistas presionaban al Presidente y a la presidencia para que clarificara su postura ideológica. Él enfatizó un nosotros inclusivo (Verón, 1987) acerca de su mandato:

Somos un gobierno progresista y democrático, socialista, solidario con quienes menos tienen. Jamás, óigase bien, jamás vamos a irrespetar al pueblo y a tocar sus derechos. No vamos a convertirnos en instrumento de los intereses de quienes han tenido el poder a lo largo de la historia. Nacimos revolucionarios y nos mantenemos firmes en nuestras convicciones (Presidencia de la República del Ecuador, 2018a). 
Moreno recurre a la enumeración para enfatizar su postura ideológica: los socialistas, progresistas y revolucionarios son parte del nosotros. Así, su prodestinatario está incluido en los mismos colectivos de identificación. Ante sus acercamientos con la oposición y los grupos de poder económico en el marco del diálogo que impulsaba, el mandatario explicó la relación con quienes serían -en un inicio- sus contradestinatarios: No demostrar enfrentamiento político e ideológico con ellos, tampoco -como indica van Dijk- una heterorepresentación negativa, a pesar de que mediante una metáfora los coloca en una posición opuesta: "Nosotros con la derecha ecuatoriana estamos en veredas distintas" (Presidencia de la República del Ecuador, 2018b).

Sin embargo, Moreno también argumentó que no existe mejor identidad ideológica que aquella que, en la práctica, ofrece los mejores resultados (CNN de Chile, 2018). En otras palabras, los conceptos de izquierda y derecha se anularían, como si las prácticas políticas carecieran de ideología. La derecha queda, así, sin una ubicación certera: ni en los otros, ni con el nosotros. Como afirman Albán y Velasco (2018), hay "una fuerte transformación discursiva que pone de lado el posicionamiento ideológico o fundamento político" (p. 11). Según la revisión y análisis de discursos para este estudio, al menos tras conformar el nuevo gabinete con autoridades del ala de derecha empresarial en mayo de 2018, Moreno no volvió a referirse a su postura ideológica en el resto de ese año.

\subsection{2. “El gobierno de todos"}

El único colectivo de identificación constante fue "El gobierno de todos", aunque no con la misma potencia de la "Revolución Ciudadana" utilizada en la administración previa, que se apoyaba en la constante reiteración. Por el contrario, con Moreno “estas categorías pierden sentido en su totalidad. De hecho, la reiteración no existe, ya que un alto porcentaje de la carga significativa se traduce en la acción, en las intenciones y propósitos" (Albán \& Velasco, 2018, p. 12). La disminución del énfasis en el colectivo muestra que no hay necesidad de generar identificación con un nosotros para un proyecto político, que solo se apoya para acciones coyunturales que surjan del gobierno.
“El Gobierno de todos" tiende a ser equiparado con el consenso o el diálogo y se vuelve un eslogan institucional para las cadenas nacionales, para cerrar sus discursos con esa frase o como argumento para justificar su toma de decisiones. No tiene un prodestinatario, el colectivo de identificación está excluido y el "todos" ocupa su lugar. Se describe como gobierno de la gente, responsable, progresista y democrático (Presidencia de la República del Ecuador, 2018a). Se opone, además, a la confrontación y polarización y asegura que es un gobierno transparente (Presidencia de la República del Ecuador, 2018c).

Indagamos la construcción pronominal en los discursos de Moreno con la conjugación "somos", con la que el mandatario nombra, por ejemplo, que "somos": coterráneos, colegas, hermanos, diversos, extremadamente emotivos, sentimentales y solidarios. En estos elementos resaltan aspectos identitarios y emocionales, pero no del orden político.

\subsection{Los nuevos otros: los corruptos y sus excorreligionarios}

Como indicó Verón, al ser un discurso político existe confrontación con otros enunciados. En este caso, identificamos alusiones interdiscursivas (Maingueneau \& Plantin, 2005) con actos de descalificación a categorías que eran utilizadas por los actuales opositores de Moreno, quienes fueron previamente sus aliados.

\subsubsection{Alianza PAIS, Revolución Ciudadana y el Socialismo del siglo XXI}

Moreno promueve una significación diferente de los meta colectivos a los que antes pertenecía, mantiene una denominación positiva sobre el proceso político inicial, pero da un carácter negativo a otros momentos de lo que fue el gobierno de la Revolución Ciudadana (los califica de "siniestros") y desecha el uso del mismo colectivo de identificación para su mandato.

Moreno manifestó que las condiciones cambiaron por la confrontación que generó el expresidente Correa: "Parecíamos esos matones de barrio, esos guambras machísimos de la escuela que pasan co- 
deándole a uno, para que el otro reaccione y diga ¡qué le pasa!' y enseguida le caiga a trompones" (Presidencia de la República del Ecuador, 2018d). En sus discursos, Moreno recurre a la anécdota, a las experiencias cotidianas o a refranes y sabiduría populares (Minervini, 2017).

Para inicios de 2018, Moreno sostenía discursivamente a Alianza PAIS como un colectivo de identificación, aunque sin nombrarlo frecuentemente. Este colectivo contenía al prodestinatario que se ubicaba como partidario político. Se trataría de una agrupación con principios fundacionales sólidos, que revisó su pasado, encontró sus errores y los enmendó (Presidencia de la República del Ecuador, 2018b).

Sin embargo, más tarde, este colectivo que originalmente era considerado como un nosotros de identificación, había perdido peso y presencia discursiva. En efecto, Alianza PAIS se había transformado, más bien, en un significante que representaba negativamente al otro del pasado: "Alianza PAIS, sí, mi partido, también fue responsable (...) de exacerbar la disputa y de permitir que la ira domine los argumentos" (Presidencia de la República del Ecuador, 2018e). Discursivamente, Moreno ubica a su colectivo bajo una "lectura destructiva" -indica Verón- que define una posición de adversario contra su propio movimiento político.

El presidente Moreno también resignifica otro meta colectivo, como es el conformado por los gobiernos de izquierda contemporáneos en la región agrupados bajo la etiqueta de Socialismo del siglo XXI ${ }^{9}$. Para Moreno, dicho proyecto regional perdió también cualquier connotación positiva y lo vincula al gobierno anterior: "El progresismo ecuatoriano, el progresismo latinoamericano, aquello que nosotros llamamos el Socialismo del siglo XXI lastimosamente se prostituyó al momento en que empezaron los actos de corrupción" (CNN de Chile, 2018).

\subsubsection{Sobre los corruptos}

Es uno de los asuntos centrales en los discursos del Presidente Moreno en cuanto a la construcción de los otros. La crítica a los corruptos y la corrupción es una idea potente, en tanto fenómeno, pues cobra un poder explicativo que permite hacerla inteligible fácilmente de forma negativa en el sentido común.

Primero, los corruptos son un contradestinatario generalizado al ser una problemática del país. Moreno coloca a este elemento como sustantivo y adjetivo: corruptos, empresas corruptas, gente corrupta, círculo corrupto, ex autoridades jerárquicas encarceladas por corrupción. Al ser nominalizados, se despersonaliza quiénes son sus ejecutantes y los factores que inciden para su existencia.

El mandatario también pasa de la generalización a una cuantificación y enumeración de sus contradestinatarios: "vicepresidente encarcelado, ministros encarcelados, altos funcionarios encarcelados y un contralor prófugo"10 (Presidencia de la República del Ecuador, 2018b). Además, Moreno alude a quienes integran el grupo que apoya al expresidente, Rafael Correa, quienes, a su vez, califican a Moreno como "traidor":

cuando me dijeron a mí: hay que cuidar a los compañeros, no me dijeron hay que cuidar a los compañeros corruptos porque yo hubiera dicho: "no". Porque la lealtad no es con las personas, es con los principios, la lealtad con la patria. No es la lealtad de la mafia pues (...) en esas circunstancias prefiero que me pongan de traidor (Presidencia de la República del Ecuador, 2018d).

Moreno dialoga interdiscursivamente con las críticas que sus ahora opositores efectúan contra él, las incluye para reconfigurarlas a su favor. Efectúa una negación polémica (Ducrot, 1984) de la argumentación de esos otros y anula ese discurso al revertir la concepción de lealtad de quienes lo acusan. Por el contrario, Moreno los representa a quienes lo atacan como una "mafia" y "compañeros corruptos".

\section{Componentes: desdibujar y volver a dibujar}

Siguiendo a Verón (1987), los componentes describen cómo el enunciador desarrolla su red de relaciones con las entidades del imaginario. Verón propone cuatro tipos de componentes que están 
entretejidos. El componente descriptivo permite la constatación y hace un balance de una situación. El segundo es el didáctico para enunciar principios o verdades universales. El prescriptivo aborda el orden del deber y efectúa imperativos deontológicos. Finalmente, el programático tiene el componente del futuro en el discurso político.

Al indagar la construcción del nosotros y los otros, este estudio enfatiza el componente descriptivo (sin descartar por completo los demás), en el que el enunciador analiza la situación con lecturas del pasado y del presente. En este componente, Moreno se advierte como fuente privilegiada de la inteligibilidad de esa historia narrada y difunde sus evaluaciones sobre la misma (Verón, 1987). Este es el apartado que más información proveyó: el objetivo de la gestión discursiva de Moreno sería ejercer una relectura abundante del pasado y de legitimar su gobierno con la remediación de lo realizado por su predecesor.

\subsection{El inicio de Rafael Correa y su cambio}

Moreno reitera que hubo dos etapas en la Revolución Ciudadana y lo argumenta de forma relacional (Doury, 2016) para establecer sus acuerdos y diferencias con ellas. Dibuja a Correa en los inicios del proceso como un joven lleno de ideales de cambio para un país que estaba en manos de poderes fácticos. En esa discursividad, Moreno articula una representación positiva de ese primer momento, en el que él se postulaba como candidato y ejercía como vicepresidente con obras a favor de los desposeídos. Moreno resalta que se produjo un cambio cuando Correa impulsó la posibilidad de postulación indefinida al cargo, con el consecuente riesgo de perpetuarse en el poder. Para entonces, Moreno ya no formaba parte del gobierno de Correa. De ahí que Moreno configura dicho momento como de perversión moral (CNN de Chile, 2018) causada por la posesión del poder.

A inicios de 2018 se verifica un tratamiento formal como "economista Rafael Correa", sin adjetivaciones o metáforas polémicas. Sin embargo, Moreno lo deslegitima mediante el relato en su conjunto. Meses después, Moreno incrementó la representación negativa de Correa de forma directa, con interdiscursos ante las críticas mutuas. Por ejemplo, Moreno cree que Correa denota una "compresión sicológica" e "insuficiencias internas" (Presidencia de la República del Ecuador, 2018b). Moreno hizo también un símil de Correa con el nibelungo larquetipo recreado en el libro El Señor de los Anillos como Sméagol/Gollum y masificado luego en la trilogía cinematográfica del mismo nombre), personaje que adquiere un poder siniestro y transforma su ser (CNN en Español, 2018). Así, retrata a Correa como un monstruo, un otro radical en la política.

En cuanto a una lectura del presente (Moreno en la presidencial, dibuja a Correa como el causante de la ruptura política porque el expresidente habría dejado intencionadamente al país en malas condiciones para volver, más tarde, como "redentor" (CNN de Chile, 2018).

\section{2. "La mesa (no) servida" y problemas heredados}

“Desde hace un año, todos los días estamos descubriendo - con asombro y desilusión, lastimosamente- que la mesa estaba vacía. ¡Se lo llevaron todo!" (Presidencia de la República del Ecuador, 2018e). Es otro de los elementos retóricos para apropiarse de las frases de Rafael Correa ("vamos a dejar la mesa servida") y darles un nuevo sentido con el cual configurar a ese otro.

La polifonía continúa en el discurso de Lenín Moreno, quien explicó en qué consiste "la mesa no servida" o "la mesa vacía": "en alusión alegórica de lo que había hecho el presidente anterior (...) ahora una vez que sabemos que estamos sobreendeudados, que le debemos a todo el mundo" (Presidencia de la República del Ecuador, 2018b). Se trata de una "alusión alegórica", una representación de las acciones del exmandatario, para criticarlo y desmentirlo. Otro tema del debate interdiscursivo entre Correa y Moreno era respecto a cuánto ascendía el monto total de la deuda pública. El relato de Moreno decía que, al sincerar esa deuda, descubrió que recibió un país “quebrado económicamente" (Presidencia de la República del Ecuador, 2018c).

Aquí tenemos otro ejemplo metafórico, en cambio, para dibujar el presente: "Ha sido un año de poner la casa en orden. (...) Ha sido una limpieza seria, transparente, responsable, democrática. Recurri- 
mos a la consulta popular y al referéndum para que esa limpieza la hagamos entre todos" (Presidencia de la República del Ecuador, 2018e). Alude al uso de una frase del uso cotidiano sobre el mantenimiento responsable del hogar. Esto, Moreno lo traslada al manejo del gobierno para "limpiar", mediante la consulta popular ${ }^{11}$, lo que hizo previamente Correa bajo su gestión.

\subsection{La "cirugía mayor" para combatir la corrupción}

Uno de los elementos discursivos más fuertes de Moreno ha sido la metáfora sobre la "cirugía mayor" (Presidencia de la República del Ecuador, 2018f) para lo que califica de su lucha contra las irregularidades del mandato de Correa, a quien Moreno denomina explícitamente como "corrupto". Es una metáfora de orden médico para extirpar ese "cáncer" de la corrupción que afecta al cuerpo social del Ecuador.

Los discursos de Moreno desarrollan una narración continua sobre los actos irregulares. En ellos, el mandatario afirma que, en el gobierno anterior, cometieron delitos estratégicamente, de forma articulada y sistemática, con el propósito de no ser descubiertos al permanecer en un "círculo oscuro, siniestro y corrupto".

La negación polémica (Ducrot, 1984) es un recurso muy utilizado por Moreno, ya que no puede representar negativamente todo el gobierno anterior ya que fue parte de él, pero tiene que negarlo añadiendo nuevos elementos que le permitan legitimarse: "Se hicieron grandes obras, importantes obras sin duda, pero lamentablemente muchas solo sirvieron para que esos pocos se enriquezcan ilegalmente" (Presidencia de la República del Ecuador, 2018f).

El recurso de la enumeración es clave en el discurso de Moreno: da a conocer varios casos judiciales investigados contra el mandato de Correa. Por ejemplo, sobreprecios en proyectos como la Refinería de Esmeraldas, la Refinería del Pacífico, el Poliducto Pascuales-Cuenca, en ventas petroleras, la construcción de carreteras y el hospital en Monte Sinaí (Presidencia de la República del Ecuador, 2018e).

\subsection{Polarización, confrontación y libertad de expresión}

“Todos estaban distanciados por la política. ¡Esa realidad no va más!" (Presidencia de la República del Ecuador, 2018e) son afirmaciones que alimentan una lectura de Moreno acerca del pasado, del gobierno de Correa en el que se habría extendido la pelea con diversos actores sociales ly Moreno los nombra: ecologistas, indígenas, trabajadores, maestros, médicos, militares, policías) (Presidencia de la República del Ecuador, 2018d). Esa es, también, una lectura acerca de lo que él desearía bajo la lógica del consenso: Anular la confrontación en la política y gobernar con tolerancia y respeto.

Moreno resalta que existió un Estado de propaganda como impulsor de aquella confrontación que afectaba la libertad de expresión, para lo cual propone -como componente programático para el presente y futuro- un "Estado de comunicación bidireccional de diálogo", entre autoridades y ciudadanos (Presidencia de la República del Ecuador, 2018e).

Sin embargo, el discurso de Moreno presenta ambivalencias. Si, por un lado, promueve valores democráticos, por otro, deslegitimó las protestas sociales que estallaron en los últimos meses de 2018 a causa de disintas medidas gubernamentales:

Ecuador vive ahora una democracia plena y real (...) hay libertad, libertad de expresión, de manifestación, libertad de reunión y, sobre todo, autonomía e independencia de todas las funciones. Entiendo que cuando hay total libertad -sobre todo luego de que ésta ha sido coartada durante mucho tiempo- se pueden producir manifestaciones y pronunciamientos que no siempre reflejan el sentir de la mayoría (Presidencia de la República, 2018g).

Su nosotros marca límites como "la mayoría" y se restringe solo a quienes creen en sus postulados la los cuales considera como absolutos pues afirma que hay "total libertad" y "democracia plena"), deslegitimando, mediante la negación polémica, los discursos y también las acciones políticas de grupos sociales emergentes. Entonces, el intento de consenso se rompe por la vía del litigio y del antagonismo frente a las desigualdades sociales. 


\section{Discusión y conclusiones}

La estrategia de los discursos de Lenín Moreno durante 2018 proyecta el cambio de lógica del gobierno desde un enfoque confrontacional hacia una política de consenso. Este sería el núcleo invariante -como enuncia Verón (1987)- en sus elocuciones. Su objetivo fue ampliar su base de apoyo y legitimar sus giros en la articulación de fuerzas políticas que se alejan de la izquierda y del gobierno de Rafael Correa, en general, y de la persona del expresidente, en particular, con lo cual Moreno implementó modificaciones en sus políticas económicas encaminadas a un debilitamiento de lo público.

Esta lógica del consenso permitió la inexistencia de opositores y contradestinatarios más allá de Correa y su mandato previo. En sus discursos, Moreno atribuyó todos los males del país en materia económica y de corrupción a su antecesor y su gestión, omitiendo las condiciones estructurales que han permitido y alimentado las desigualdades sociales en Ecuador. Al contrario, a través del consenso cuidadosamente cultivado mediante la producción discursiva gubernamental, la gestión de Moreno impulsó una inmovilidad social y ocultó su articulación con las élites de poder.

Los resultados de este análisis indican las siguientes etapas: en la primera, Moreno mantiene apego a su pertenencia ideológica y partidista, en su caso a la izquierda y a la Alianza PAIS. En transición, Moreno incrementa el número y la agresividad de los ataques hacia Correa en un intento explícito por diferenciarse de él. En una segunda etapa se radicaliza su alejamiento de Correa y se desprende, también, de su identificación ideológica y partidaria para adoptar una postura institucional discursiva únicamente desde el gobierno.

Hay una formación débil de prodestinatarios. El colectivo de identificación "El Gobierno de todos" no incluye a sus correligionarios y se vuelve una generalidad que oculta la construcción del nosotros y de los otros en el campo político. Esto tras dejar fuera a sus prodestinatarios socialistas o revolucionarios -como él indicaba al inicio de su mandato- para ampliar su base de apoyo con ciudadanos y líderes de tendencias ideológicas diversas.
En cambio, sí es clara la construcción de los otros por parte de Moreno: Rafael Correa, sus aliados y su antiguo gobierno. En su producción discursiva, Moreno deslegitima y representa como corruptos a todos los colectivos de identificación que antes eran usados por la gestión anterior, como la Revolución Ciudadana y el Socialismo del siglo XXI. En otras palabras, Moreno convierte progresivamente a su antiguo nosotros en su nuevo otro. Esto lo enfatiza Moreno con sus lecturas del pasado y del presente al proponer una reescritura de la historia política reciente del país.

Una de las limitaciones de este artículo es no incluir elementos de discursos contemporáneos que son más complejos, como audiovisuales, texto, imagen y sonido, los cuales tienen relevantes roles en la comunicación política por la convergencia mediática y la potenciación de las nuevas tecnologías. Esto podrá abordarse en futuras investigaciones.

Este estudio contribuye al campo de la comunicación política porque el corpus analizado demuestra la transformación discursiva de un líder en un contexto regional políticamente convulso: Si bien Moreno sobresalió en un inicio a través del denominado "Giro a la izquierda", él mismo encarnó el declive de esa tendencia y la abandonó paulatinamente. Moreno renunció a estrategias discursivas que buscaran e incentivaran el antagonismo ante las élites y grupos tradicionales de poder, a diferencia de líderes de la izquierda latinoamericana contemporánea, como su antecesor Rafael Correa o el fallecido presidente venezolano, Hugo Chávez.

Por el contrario, la estrategia de Moreno fue asumir el consenso como principal elemento de su discurso para neutralizar y bloquear el litigio social. El corpus analizado se proyecta como un factor para conseguir la pasividad de los sujetos en un contexto localizado ante gobiernos que pretenden ejercer el poder sin la práctica ciudadana de la política. Esta estrategia ahora es una constante impulsada por gobiernos contemporáneos de distintas tendencias, buscan instaurar efectos de sentido en los ciudadanos para legitimar su mandato y ocultar la construcción de los otros y nosotros. 


\section{Notas}

1. El Movimiento Alianza PAIS - Patria Altiva i Soberana fue fundado en 2006 con una orientación política de izquierda. Ha gobernado Ecuador desde 2007 hasta 2020.

2. Se transmitió entre 2007 y 2017 los sábados de 10:00 a 13:00 hrs. En este, el expresidente Correa informaba las obras inauguradas y proyectos. Incluía espacios de opinión, artistas en vivo y para atacar a opositores.

3. En 2008, la Agencia de Garantía de Depósitos incautó a Gamavisión y TC al Grupo Isaías, expropietario del quebrado Filanbanco. A sus representantes sentenciaron por peculado bancario en la crisis en Ecuador en 1999. La incautación fue para recuperar fondos para acreedores y el Estado. Más información ver: Abad, G. (2010) El club de la pelea... Poder político vs. poder mediático. En: Rincón, O. (editor) ¿Por qué nos odian tanto? Bogotá: Centro de Competencia en Comunicación para América Latina Friedrich Ebert Stiftung

4. El Telégrafo es propiedad del Estado ecuatoriano y ha funcionado bajo una lógica oficialista en los gobiernos de Correa y Moreno. Fue incautado en 2008 tras estar vinculado al Banco del Progreso, que quebró fraudulentamente en la crisis de 1999.

5. Otto Sonnenholzner es economista, con estudios de posgrado en Alemania, empresario de la comunicación y líder gremial de la radiodifusión. Es el tercer vicepresidente que tuvo Ecuador en el gobierno de Lenín Moreno, tras las destituciones de Jorge Glas y María Vicuña. En diciembre de 2018, Sonnenholzner fue designado por la Asamblea Nacional de una terna enviada por Moreno.

6. La Ley de Comunicación fue aprobada durante el gobierno de Rafael Correa en 2013. Sectores de oposición y medios de comunicación privados la llamaron "ley mordaza”, además acusaron a la Superintendencia de Información de persecución.

7. En 2018, las frecuencias de los medios estaban asignadas así: $88.45 \%$ a privados, $5.82 \%$ a públicos y $5.73 \%$ a comunitarios, según el Consejo de Comunicación.

8. La palabra "guambra" proviene del quichua huambra, significa: muchacho, niño o adolescente. Mientras que "trompones" se refiere a puñetazo o golpe, entendido en un contexto de pelea callejera.

9. Ideología de gobiernos y movimientos progresistas en Latinoamérica, tendencia también denominada como giro a la izquierda. Más información ver: Stoessel, S. (2014). Giro a la izquierda en América Latina del siglo XXI. Revisitando los debates académicos. Polis (39), 123-149. http://dx.doi.org/104067/ S0718-65682014000300007.

10. En 2018 estaban procesados el exvicepresidente Jorge Glas y el exministro de Energía, Aleksey Mosquera, además, el Contralor Carlos Pólit estaba prófugo en EE.UU., todos por la trama de corrupción de Odebrecht. También estaban en prisión el ex ministro de Hidrocarburos Carlos Pareja Yanuzzelli y Álex Bravo, ex gerente de la empresa estatal Petroecuador.

11. La Consulta Popular constó de 7 preguntas, entre las más relevantes: Inhabilitar a sentenciados por corrupción para participar en política; prohibir la reelección por más de una vez en cargos de elección popular; reestructurar los miembros del Consejo de Participación y derogar la "Ley de Plusvalía". En las siete preguntas, se impuso la opción "Sí" promovida por el gobierno de Moreno.

\section{Referencias}

Abad, G. (2010) El club de la pelea... Poder político vs. poder mediático. En: Rincón, 0. (editor) ¿Por qué nos odian tanto? Bogotá: Centro de Competencia en Comunicación para América Latina Friedrich Ebert Stiftung

Albán, E. \& Velasco, M. (2018). El discurso político de posesión en Ecuador, de la Revolución Ciudadana de Rafael Correa a Alianza PAIS de Lenín Moreno. Tsafiqui, Revista de investigación científica (10). https://doi.org/10.29019/tsafiqui.v0i10.403 
CNN de Chile. (14 de marzo de 2018). Presidencia de la República del Ecuador-Entrevista del Presidente Lenín Moreno con CNN de Chile. Recuperado en enero de 2020, de Youtube: https://www.youtube.com/watch?v=7GX07h3Dd6k

CNN en Español. (18 de abril de 2018). Presidencia de la República del Ecuador-Entrevista del Presidente Lenín Moreno con CNN. Recuperado en enero de 2020, de Youtube: https://www.youtube.com/watch?v=tb9HwjCIVv4

Doury, M. (2016). Argumentation. Analyser textes et discours. Paris: Armand Colin.

Ducrot, 0. (1984). El decir y lo dicho. Buenos Aires: Hachette.

Ganuza, C. (2019). Deconstrucción del orden político de Ecuador mediante el análisis crítico de los discursos de Lenin Moreno (2017-2018). Revista Scientific, 4 (14), 2443. https://doi.org/10.29394/Scientific.issn.2542-2987.2019.4.14.1.23-43

Laclau, E. (2005). La razón populista. Buenos Aires: Fondo de Cultura Económica.

Maingueneau, D. (2012). Que cherchent les analystes du discours? Obtenido de www.aad. revues.org/1354

Maingueneau, D. \& Plantin, C. (2005). Diccionario de Análisis del Discurso. Buenos Aires: Amorrortu.

Minervini, R. (2017). Análisis de un discurso político: la investidura de Lenín Moreno. Cultura Latinoamericana. Revista de Estudios Interculturales, 26(2), 54-73. https:// doi: 10.14718/CulturaLatinoam.2017.26.2.3

Mouffe, C. (2014). Agonística. Pensar el mundo políticamente. Buenos Aires: Fondo de Cultura Económica.

Presidencia de la República del Ecuador. (29 de enero de 2018a). El Presidente Informa. Recuperado en enero de 2020, de Youtube: https://www.youtube.com/ watch?v=6S9tH065YVc

Presidencia de la República del Ecuador. (21 de enero de 2018b). Entrevista con el Presidente de la República, Lenín Moreno. Recuperado en enero de 2020, de Youtube: https://www.youtube.com/watch?v=PWLTa6erc20\&t=288s

Presidencia de la República del Ecuador. (21 de agosto de 2018c). Cadena Nacional. Recuperado en enero de 2020, de Youtube: https://www.youtube.com/watch?v=RPG5a5Mez4

Presidencia de la República del Ecuador. (19 de enero de 2018d). Diálogo con medios de comunicación de Manabí. Recuperado en enero de 2020, de Youtube: https://www. youtube.com/watch?v=x39_jJC4sQY

Presidencia de la República del Ecuador. (24 de mayo de 2018e). El Primer año de Gobierno-Presidente Lenín Moreno. Recuperado en enero de 2020, de Youtube: https:// www.youtube.com/watch?v=KA7jygKkUyl\&t=2582s

Presidencia de la República del Ecuador. (12 de septiembre de 2018f). Cadena nacional con el Presidente de la República, Lenín Moreno. Recuperado en enero de 2020, de Youtube: https://www.youtube.com/watch?v=KoQKP0jN9Ac\&t=51s 
Presidencia de la República. (29 de noviembre de 2018g). Mensaje del Presidente Constitucional del Ecuador. Recuperado en enero de 2020, de Youtube: https://www. youtube.com/watch?v=sgAXkLOMilk

Presidencia de la República del Ecuador. (12 de abril de 2018h). Declaraciones del Presidente Lenín Moreno sobre situación de los periodistas secuestrados. Recuperado en enero de 2020, de Youtube: https://www.youtube.com/watch?v=u00-iqDGqZU

Rancière, J. (1996). El desacuerdo. Política y filosofía. Buenos Aires: Ediciones Nueva Visión.

Stoessel, S. (2014). Giro a la izquierda en América Latina del siglo XXI. Revisitando los debates académicos. Polis (39), 123-149. http://dx.doi.org/104067/S071865682014000300007 .

Van Dijk, T. (1999). El análisis crítico del discurso. Anthropos (186), 23-36.

Van Dijk, T. (1999b). ¿Qué es análisis de discurso político? En: I. Rodrigo, \& T. Van Dijk, Análisis del discurso social y político. Quito: Abya Yala.

Verón, E. (1987). La palabra adversativa. Observaciones sobre la enunciación política. En: E. Verón, El discurso político: Lenguajes y acontecimientos (págs. 11-26). Buenos Aires: Hachette.

Waisbord, S. (2014). Vox populista. Medios, periodismo, democracia. Barcelona: Gedisa.

\section{- Sobre el autor:}

Byron Andino Veloz es candidato doctoral en Comunicación de la Universidad $\mathrm{Na-}$ cional de La Plata (Argentina), magíster en Comunicación de la Universidad Andina Simón Bolívar-sede Ecuador. Periodista. Líneas de investigación: estudios de recepción, análisis de discurso, comunicación y política. Ecuatoriano.

\section{- ¿Cómo citar?}

Andino, B. (2020). El nosotros y los otros en los discursos del presidente ecuatoriano Lenín Moreno durante 2018. Comunicación y Medios, (41), 29-41, doi: 10.5354/07191529.2020 .55926 